with people with a severe mental illness is inadequate. Whatever the experience of your correspondent, the reality on the ground is that many officers faced with a desperately ill person behaving in a bizarre manner respond inappropriately. It has taken a number of deaths during restraint and the controversy surrounding the use of CS spray on people with a severe mental illness to bring home this point to everyone.

During meetings with the Association of Chief Police Officers (ACPO) it has become apparent to us that ACPO guidelines are no more than that: the individual forces largely determine their own approaches to restraint and the use of CS spray. The National Schizophrenia Fellowship is seeking positive partnership, we have worked with over 4000 police officers at 10 conferences in the last two years.

The Metropolitan Police is establishing specialist multi-agency teams to overcome present shortcomings. What a pity that health and social services are not taking the lead in London and elsewhere to reduce the need for the police to be involved to an absolute minimum.

ClifF PRIOR, Chief Executive, National Schizophrenia Fellowship, 28 Castle Street, Kingston upon Thames, Surrey KT1 1SS

\section{Management of pre-pubertal children with gender identity disorder}

Sir: I am writing in regard to the Royal College of Psychiatrists, Council Report CR63, published in January 1998, regarding Gender Identity Disorders in Children and Adolescents. I draw your attention to the advice given on management on page 4: "where children or adolescents meet the criteria of a gender identity disorder under DSM-IV or ICD-10, there should be a referral for assessment and/or treatment in a multi-disciplinary gender identity specialist team which includes the input of child and adolescent mental health."

I am currently only aware of one such specialist service for gender identity disorder currently in Britain. based at the Portman Clinic in London. Although this clinic accepts referrals from outside the area I cannot help but wonder what sort of service could be offered to someone who lives a long way away. Perhaps the possibility of consultation for any professionals involved in a case. at the Portman Clinic, is more promising.

I also draw your attention to the line provision of consultant/liaison arrangements with a paediatric endocrinologist for the purpose of physical assessment, education about growth, endocrine issues and involvement in any decision about physical interventions.'
I would argue that it would be helpful if the report clarified when the involvement of a paediatric endocrinologist should be sought. It would seem sensible to make a distinction between the pre- and post-pubertal period and a referral made pre-pubertally, only if the clinician, child or carers have particular concerns about the hormonal state of the child or when there is a demand for physical intervention.

All these questions have clinical relevance to a case that I am currently seeing. It involves an eight-year-old with gender identity disorder. After reading the report I wondered whether I should be trying to manage this case locally or whether the case should be referred on.

Finally, I should like to echo the emphasis made in the report, upon assessment and subsequent therapy for individuals with gender identity problems and their families. This is indicated both to explore the core disorder and any associated emotional and behavioural problems. The need for therapy seems paramount in the pre-pubertal stage because of the greater fluidity of sexual development at this age and the hope that a more appropriate gender identification emerges as described in a case seen by Habner (1991).

HABNER, D. H. (1991) The psychoanalytic treatment of a pre-school boy with gender identity disorder. Joumal of the American Psychoanalytic Association, 39. 107-129.

ROYAL COLLEGE OF PSYChIATRISTS (1998) Gender Identity Disorders in Children and Adolescents. Guidance for Management. Council Report CR63. London: Royal College of Psychiatrists.

DAVID A. WHITE, Specialist Registrar in Child and Adolescent Psychiatry. Yorkshire Deanery, Child and Adolescent Service, 123 Little Horton Lane, Bradford BD5 OHT

\section{Gender identity development service}

Sir: Council Report CR63 is a first attempt to establish a framework for the management of an unusual and complex condition. Some issues in management, such as when to start hormonal interventions during adolescence, are controversial (Cohen-Kettenis \& van Goozen, 1998) and the Report will change as clinical experience and research progresses. 'Referral' in the Report is intended in a broad sense, as this could include consultative work as Dr White suggests. In fact, it is my view that the support which a specialist service can offer to local services has to be flexible and negotiable according to the needs of the patients and of the local service.

In our service, following a referral, we will sometimes offer an assessment, and then we would negotiate a shared programme of management with the local service. This may include 
individual therapy for the child (usually offered locally), parental counselling, six monthly group meetings for parents (held in London), assessment by our specialist paediatric endocrinologist and professional network meetings (held locally; di Ceglie, 1998). Alternatively, the specialist service may offer consultation only to professionals in the local child psychiatric team.

I agree with Dr White that the issues for which a consultation with a paediatric endocrinologist is sought before and after puberty can be different. It will be part of the assessment and ongoing management and therapy to determine which issues need the opinion and recommendation of the paediatric endocrinologist.

As many interventions with child, family and school are undertaken in parallel or at different stages it is crucial that there is good coordination among the various professionals involved and that timing of interventions is carefully considered. It is here that the resources and experience of a psychiatric specialist service are best employed.

Cohen-Kettenis P. T. \& van Goozen S. H. M. (1998) Pubertal delay as an ald in diagnosis and treatment of a transsexual adolescent. European Child \& Adolescent Psychiatry. 7, 246-248.

Di Cegue, D. (ed.) \& Freedman, D. (1998) A Stranger in My Own Body. London: Karnac.

DOMENICO DI Ceglie, Consultant Child \& Adolescent Psychiatrist, Adolescent Department, Tavistock Clinic, and Director, Gender Identity Development Unit, Portman Clinic, 8 Fitzjohn's Avenue, London NW3 5NA

\section{Women and old age poychiatry}

Sir: At the Faculty of Old Age Psychiatry residential conference in Cardiff (March 1999) there were 226 listed delegates of whom $43 \%$ were women. No session was chaired by a woman. No short paper was presented by a woman. Of 13 workshop presenters three $(23 \%)$ were women. and of 19 poster presenters eight were women (42\%). Two eminent women, Professor Elaine Murphy and Lady Sally Greengross, presented invited papers in the final session (50\% women).

One of the speakers in the short papers session commented on the absence of women and I feel it is important to reflect on this. The Faculty of Old Age Psychiatry should not be identified as a particular offender, as I suspect these findings are typical of College academic meetings. Old age psychiatry has a high proportion of women in consultant posts and in training posts. Why was our residential conference male dominated?

Are women trainees less likely to submit abstracts to academic meetings? Are women more likely to submit posters than oral papers: if so, why? Do women choose to investigate topics which are less attractive to or valued less by the men who select out abstracts for presentation? Are male trainees more likely to volunteer presentations? Should trainers be encouraging female trainees more actively? I have resolved to work harder on encouraging trainees to offer presentations. Should we do more?

SUSAN M. BENBOW, Consultant Psychiatrist lOld Age Psychiatry), Carisbrooke Resource Centre, Wenlock Way, Gorton, Manchester M12 5LF 